\title{
Ultrasonographic assessment of reticuloruminal motility in 45 cows
}

\author{
Braun, Ueli ; Schweizer, A
}

\begin{abstract}
The goal of this study was to investigate the feasibility of ultrasonographic assessment of reticuloruminal motility in 45 healthy cows. The transducers of five ultrasound machines were connected to a digital video recorder and placed simultaneously at five sites on the left side of the cows to scan the reticulorumen (reticulum; ruminal atrium; dorsal sac of the rumen; left longitudinal groove; ruminal recess, caudodorsal and caudoventral blind sacs). The video streams from all five ultrasound machines were recorded synchronously with the same time line and displayed on a single monitor. Time 0 was defined as the start of a biphasic reticular contraction. The reticulum was visualised in all cows and had $11.0 \pm 2.12$ biphasic contractions in 9 min. The ruminal atrium was visualised in $40(89 \%)$ cows and had $10.7 \pm 2.10$ contractions in $9 \mathrm{~min}$, which started at the time point $5.0 \pm 0.83 \mathrm{sec}$ and lasted $7.0 \pm$ $2.14 \mathrm{sec}$. Contractions of the dorsal sac of the rumen, visible in all cows, were visualised in 29 (64\%) cows. There were $9.5 \pm 1.8$ contractions in 9 min that started at the time point $4.0 \pm 0.85$ sec and lasted $8.2 \pm 1.04 \mathrm{sec}$. The left longitudinal groove was seen contracting in $39(87 \%)$ cows. There were $10.2 \pm 1.98$ contractions in $9 \mathrm{~min}$ that started at the time point $4.1 \pm 1.81 \mathrm{sec}$ and lasted $7.8 \pm 1.19$ sec. Contractions of the ventral sac of the rumen (ruminal recess) were seen in 31 (69\%) cows. There were $7.5 \pm 2.59$ contractions in 9 min that started at the time point $14.3 \pm 4.30$ sec. Contractions of the caudodorsal and caudoventral blind sacs were seen in $34(76 \%)$ cows. There were $9.0 \pm 2.75(1.0 \pm 0.31)$ contractions/min and $9.4 \pm 2.09(1.0 \pm 0.23)$ contractions/min of the dorsal and ventral blind sacs, and they started at the time points $6.2 \pm 1.32 \mathrm{sec}$ and $21.3 \pm 6.20 \mathrm{sec}$, respectively. Primary contraction cycles were seen in all cows and secondary cycles in $22(49 \%)$ cows. The former were complete in 37 $(82 \%)$ cows and incomplete in $8(18 \%)$. There were $11.0 \pm 2.12$ primary and $4.5 \pm 2.15$ secondary cycles in $9 \mathrm{~min}$, and the ratio between primary and motilisecondary cycles averaged 2.4:1. Ultrasonography is suitable for the assessment of reticuloruminal motility in cattle.
\end{abstract}

DOI: https://doi.org/10.17236/sat00007

Other titles: Ultrasonographische Beurteilung der Hauben- und Pansenmotorik bei 45 Kühen

Posted at the Zurich Open Repository and Archive, University of Zurich

ZORA URL: https://doi.org/10.5167/uzh-110709

Journal Article

Accepted Version

Originally published at:

Braun, Ueli; Schweizer, A (2015). Ultrasonographic assessment of reticuloruminal motility in 45 cows. Schweizer Archiv für Tierheilkunde, 157(2):87-95.

DOI: https://doi.org/10.17236/sat00007 


\title{
Ultrasonographic assessment of reticuloruminal motility in 45 cows
}

\author{
U. Braun, A. Schweizer
}

Department of Farm Animals, Vetsuisse Faculty, University of Zurich

\section{Summary}

The goal of this study was to investigate the feasibility of ultrasonographic assessment of reticuloruminal motility in 45 healthy cows. The transducers of five ultrasound machines were connected to a digital video recorder and placed simultaneously at five sites on the left side of the cows to scan the reticulorumen (reticulum; ruminal atrium; dorsal sac of the rumen; left longitudinal groove; ruminal recess, caudodorsal and caudoventral blind sacs). The video streams from all five ultrasound machines were recorded synchronously with the same time line and displayed on a single monitor. Time 0 was defined as the start of a biphasic reticular contraction. The reticulum was visualised in all cows and had $11.0 \pm 2.12$ biphasic contractions in $9 \mathrm{~min}$. The ruminal atrium was visualised in 40 (89\%) cows and had $10.7 \pm$ 2.10 contractions in $9 \mathrm{~min}$, which started at the time point $5.0 \pm 0.83 \mathrm{sec}$ and lasted $7.0 \pm 2.14$ sec. Contractions of the dorsal sac of the rumen, visible in all cows, were visualised in 29 (64 $\%$ ) cows. There were $9.5 \pm 1.8$ contractions in 9 min that started at the time point $4.0 \pm 0.85$ sec and lasted $8.2 \pm 1.04 \mathrm{sec}$. The left longitudinal groove was seen contracting in 39 (87\%) cows. There were $10.2 \pm 1.98$ contractions in 9 min that started at the time point $4.1 \pm 1.81$ sec and lasted $7.8 \pm 1.19 \mathrm{sec}$. Contractions of the ventral sac of the rumen (ruminal recess) were seen in $31(69 \%)$ cows. There were $7.5 \pm 2.59$ contractions in 9 min that started at the time point $14.3 \pm 4.30 \mathrm{sec}$. Contractions of the caudodorsal and caudoventral blind sacs were seen in $34(76 \%)$ cows. There were $9.0 \pm 2.75(1.0 \pm 0.31)$ contractions $/ \mathrm{min}$ and $9.4 \pm 2.09$ $(1.0 \pm 0.23)$ contractions/min of the dorsal and ventral blind sacs, and they started at the time points $6.2 \pm 1.32 \mathrm{sec}$ and $21.3 \pm 6.20 \mathrm{sec}$, respectively. Primary contraction cycles were seen in all cows and secondary cycles in 22 (49\%) cows. The former were complete in $37(82 \%)$ cows and incomplete in $8(18 \%)$. There were $11.0 \pm 2.12$ primary and $4.5 \pm 2.15$ secondary cycles in $9 \mathrm{~min}$, and the ratio between primary and secondary cycles averaged 2.4:1. Ultrasonography is suitable for the assessment of reticuloruminal motility in cattle.

Keywords: cattle, ultrasonography, reticular motility, ruminal motility, primary cycle, secondary cycle 


\section{Ultrasonographische Beurteilung der Hauben- und Pansenmotorik bei 45 Kühen}

Das Ziel der vorliegenden Untersuchung war es, abzuklären, ob und wie sich die

Ultrasonographie zur Beurteilung der Hauben- und Pansenmotorik beim Rind eignet. Die

Untersuchungen erfolgten bei 45 Kühen mit gleichzeitig 5 Ultraschallgeräten, deren

Schallköpfe an 5 verschiedenen Stellen von Haube und Pansen (Haube;

Pansenvorhof/kraniales Ende des ventralen Pansensacks = Pansenbucht; dorsaler Pansensack;

linke Pansenlängsfurche; dorsaler/ventraler Pansenblindsack) positioniert und an ein digitales Aufnahmegerät angeschlossen wurden. Letzteres erlaubte es, die Videoströme aller 5

Ultraschallgeräte während 9 Minuten mit gleicher Zeitachse aufzuzeichnen und auf einem einzigen Bildschirm darzustellen. Als Zeitpunkt 0 wurde der Beginn der Haubenkontraktion bezeichnet. An der Haube, die bei allen 45 Kühen dargestellt werden konnte, wurden in 9 Minuten $11.0 \pm 2.12$ biphasische Kontraktionen beobachtet. Der Pansenvorhof war bei 40 Kühen (89\%) zu sehen und kontrahierte sich 10.7 \pm 2.10 Mal, wobei die Kontraktionen $5.0 \pm$ $0.83 \mathrm{sec}$ nach der Haubenkontraktion erfolgten und 7.0 $\pm 2.14 \mathrm{sec}$ dauerten. Die Kontraktion des dorsalen Pansensacks war bei 29 Kühen (64 \%) zu sehen. In 9 Minuten wurden $9.5 \pm 1.8$ Kontraktionen ermittelt. Diese traten $4.0 \pm 0.85 \mathrm{sec}$ nach der Haubenkontraktion auf und dauerten $8.2 \pm 1.04$ sec. Die Kontraktion der Pansenfurche war bei 39 Kühen (87\%) zu sehen. In 9 Minuten traten 10.2 \pm 1.98 Kontraktionen auf. Diese waren $4.1 \pm 1.81 \mathrm{sec}$ nach der Haubenkontraktion zu beobachten und dauerten $7.8 \pm 1.19 \mathrm{sec}$. Die Kontraktion des ventralen Pansensacks (Pansenbucht) war bei 31 Kühen (69 \%) zu sehen und es wurden $7.5 \pm$ 2.59 Kontraktionen ermittelt, die $14.3 \pm 4.30 \mathrm{sec}$ nach der Haubenkontraktion auftraten. Die Kontraktion des dorsalen und ventralen Blindsacks war bei 34 Kühen (76 \%) zu sehen. In 9 Minuten wurden $9.0 \pm 2.75$ Kontraktionen des dorsalen $(1.0 \pm 0.31$ Kontraktionen/Min.) und $9.4 \pm 2.09$ Kontraktionen des ventralen Blindsacks (1.0 \pm 0.23 Kontraktionen/Min.) beobachtet. Diese traten $6.2 \pm 1.32$ bzw. $21.3 \pm 6.20 \mathrm{sec}$ nach Beginn der Haubenkontraktion auf. Bei allen 45 Kühen (100 \%) waren Primär- und bei 22 Kühen (49 \%) Sekundärzyklen zu sehen. Die Primärzyklen waren bei 37 Kühen (82\%) vollständig und bei 8 Kühen (18\%) unvollständig. In 9 Minuten wurden 11.0 \pm 2.12 Primär- und 4.5 \pm 2.15 Sekundärzyklen beobachtet. Das Verhältnis von Primär- zu Sekundärzyklen betrug durchschnittlich 2.4 zu 1 . Die Untersuchungen haben gezeigt, dass sich die Ultrasonographie eignet, um bei Kühen die Motorik von Haube und Pansen darzustellen. 
Schlüsselwörter: Rind, Ultrasonographie, Haubenmotorik, Pansenmotorik, Primärzyklus, Sekundärzyklus

\section{Introduction}

The reticulum and rumen form the so-called reticulorumen, which is responsible for mixing and breaking down digesta and is the site of microbial digestion of plant fibre. The motility is regulated by a complex system of excitatory and inhibitory inputs to the gastric centre in the medulla oblongata (Constable et al., 1990a). The general pattern of reticuloruminal motility consists of regular contraction sequences (Sellers and Stevens, 1966; Wyburn, 1980; Constable et al., 1990a; Kaske, 2005), which successively engage the various parts of the reticulum and rumen. There are primary and secondary contraction cycles; the former serve primarily to mix the ingesta, support optimal microbial fermentation and transport ingesta into the omasum (Constable et al., 1990a), whereas the latter are involved in eructation of gas (Constable et al., 1990b). Each primary contraction cycle starts with biphasic reticular contraction, which is followed by contraction of the anterior blind sac of the rumen and then contraction of the dorsal sac of the rumen in a cranio-caudal direction. The latter involves circular contraction and dorsal movement of the rumen pillars. The contraction of the caudodorsal blind sac of the rumen is the final stage of the contraction of the dorsal sac of the rumen. The primary contraction cycle concludes with contraction of the ventral sac of the rumen and its caudoventral blind sac. Secondary contraction cycles do not involve the reticulum and ruminal atrium and consist of contraction of the dorsal sac and then the ventral sac of the rumen. This pattern was discovered nearly 100 years ago using direct observation, palpation and pressure recordings (Wester, 1926; Schalk and Amadon, 1928). Further studies followed in the 50s and 60s of the last century (Reid and Cornwall, 1959; Dziuk and McCauley, 1965); pressure events were recorded with a system of strain gauges and opentipped catheters terminating in the reticulum, cranial sac, caudodorsal blind sac and ventral sac of the rumen (Dziuk and McCauley, 1965). These investigations were technically complex and therefore limited to small numbers of animals. They were also invasive because they involved fistulation of the rumen. Ultrasonography has been used successfully for the assessment of the reticulum and reticular motility (Braun and Götz, 1994; Braun and Rauch, 2008) as well as for imaging the rumen (Tschuor and Clauss, 2008; Imran et al., 2011; Braun et al., 2013). The main goal of this study was therefore to investigate the feasibility of ultrasonography for the assessment of ruminal motility. Ancillary goals were to investigate the frequency of primary and secondary contraction cycles and the relationship between 
primary and secondary cycles. To achieve this, the reticular and ruminal contraction pattern was characterized in 45 cows belonging to 3 dairy breeds using 5 ultrasound machines simultaneously with the transducers positioned at various sites over the reticulorumen.

\section{Animals, Material and Methods}

Animals

Fifteen Brown Swiss, 15 Red Holstein and 15 Holstein-Friesian cows were used. The cows were 3 to 9 years of age (mean $\pm \mathrm{sd}=5.7 \pm 1.87$ years), up to 5 months pregnant, clinically healthy and weighed between 550 and $750 \mathrm{~kg}(610 \pm 46 \mathrm{~kg})$. They were kept in tie stalls, bedded with straw and fed hay ad libitum from 06:00 to 22:00 and concentrate according to the level of production.

\section{Clinical examination}

All cows underwent clinical examination including assessment of the demeanour and general attitude, rectal temperature, heart and respiratory rates, rumen motility and fill, stratification of the rumen contents and foreign body tests. The cows were examined transrectally and by simultaneous percussion and auscultation of the abdomen on both sides. A urine sample was examined for colour, transparency, specific gravity and other characteristics using a test strip (Combur9-Test ${ }^{\circledR}$, Roche, Basel), and a rumen fluid sample was examined for colour, odour, consistency, $\mathrm{pH}$, methyl blue reduction time and chloride concentration. Because only healthy cows were used in this study, results of the examinations are not given but were presented elsewhere (Schweizer, 2012).

Preparation of cows for ultrasonography

The cows were moved to a designated room for the ultrasound examination, during which

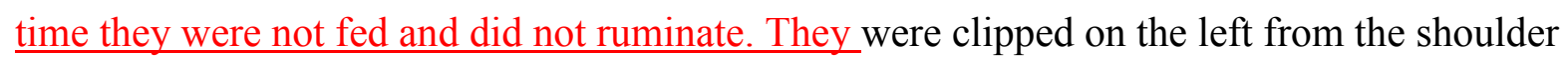
to the flank and from the dorsal midline to the ventral midline. Immediately before each examination, the skin was cleaned with alcohol, and lubricant $\left(\right.$ Vetogel $^{\circledR}$, Streuli Pharma AG, Uznach) was applied.

Ultrasound machines and 8-camera surveillance recorder The ultrasonographic examinations were conducted using five ultrasound machines simultaneously (Table 1). The five ultrasound machines were connected to a digital video recorder (VisorTech Surveillance Recorder DVR-6008 H.264 for 8 PTZ cameras, Pearl 
Switzerland GmbH, Pratteln), which recorded video streams from all five ultrasound machines synchronously and displayed them on a single monitor.

Scanning sites and examination protocol

Three examiners simultaneously placed the transducers of the 5 ultrasound machines on the left side of the cows at the sites defined below (Table 2). At each site, the target structure of the reticulorumen was identified and video recordings were made during 9 minutes.

Ultrasonographic recording at the five scanning sites

The ultrasonographic recordings at the 5 scanning sites started simultaneously and all 5 recordings had exactly the same time axis afforded by the digital video recorder. The start of a biphasic reticular contraction was defined as time point 0 , and the recordings at sites 2 to 5 were related to time 0 . The number, duration and amplitude of the contractions were determined at each site.

Primary and secondary contraction cycles

The number of primary and secondary contraction cycles in 9 minutes, and whether they were complete, was recorded for each cow. A primary ruminal contraction cycle was defined as a cycle that was preceded by biphasic reticular contraction, and a secondary ruminal contraction cycle was defined as a cycle without a preceding reticular cycle. A primary cycle was defined as complete when contractions could be recorded concurrently in the reticulum, ruminal atrium, dorsal sac of the rumen (including the caudodorsal blind sac and left longitudinal groove) and ventral sac of the rumen (ruminal recess; including the caudoventral blind sac). A secondary cycle was defined as complete when contractions occurred concurrently in the $\underline{\text { dorsal sac and in the ventral sac (ruminal recess) }}$ of the rumen. All other primary and $\underline{\text { secondary contractions were considered incomplete. }}$

\section{Statistical analysis}

Means, standard deviations and frequencies were calculated using Windows Excel 2010. Differences between the three breeds were analysed using ANOVA and t-tests provided by OpenEpi (Open Source Epidemiologic Statistics for Public Health, free and open source software). 


\section{Results}

There were no differences among the three breeds of cows and therefore the results were pooled.

Overall reticuloruminal motility

The reticuloruminal contraction started with biphasic reticular contraction (Fig. 1), which was followed closely by contraction of the ruminal atrium, the dorsal sac, the left longitudinal groove and the caudodorsal blind sac of the rumen. The caudoventral blind sac and the ventral sac of the rumen (ruminal recess) contracted on average at time point 21.3 and $31.1 \mathrm{sec}$, respectively (Tab. 3). Reticular contraction could be verified ultrasonographically in all cows and contraction of the dorsal sac of the rumen in 29 (64\%) cows; the visibility of contractions at the remaining examination sites was between these two proportions. The highest amplitude occurred during the second part of the biphasic reticular contraction measuring on average 6.1 $\mathrm{cm}$ and the smallest during contraction of the dorsal sac of the rumen measuring on average $2.2 \mathrm{~cm}$. The remaining amplitudes were between these two values.

\section{Reticulum}

The reticulum was visualised ultrasonographically in all cows confirming previous findings (Braun and Götz, 1994; Braun and Rauch, 2008). It had a crescent shape, was immediately adjacent to the peritoneum and had $11.0 \pm 2.12$ biphasic contractions in 9 minutes $(1.2 \pm 0.24$ contractions/min) (Tab. 3). The first contraction lasted $2.6 \pm 0.34 \mathrm{sec}$ and had an amplitude of $5.3 \pm 1.04 \mathrm{~cm}$, and the second contraction lasted $5.3 \pm 1.02 \mathrm{sec}$ with an amplitude of $6.1 \pm$ $0.85 \mathrm{~cm}$.

\section{Ruminal atrium}

The ruminal atrium could be visualised in $40(89 \%)$ cows at the 9 th or 10 th intercostal space (Tab. 3) and starting at time point $5.0 \pm 0.83 \mathrm{sec}$, had $10.7 \pm 2.10$ contractions in 9 minutes $(1.2 \pm 0.24$ contractions/min). The contractions lasted $7.0 \pm 2.14 \mathrm{sec}$ and the amplitude was $3.7 \pm 1.00 \mathrm{~cm}$.

Dorsal sac of the rumen

Except for the craniodorsal part, which was displaced medially by the spleen, the dorsal sac of the rumen was adjacent to the abdominal wall and could be visualised in all cows. 
Contractions were recognised in 29 cows $(64 \%)$ and were characterized by transient movement of the rumen away from the abdominal wall, during which time the dorsocaudal pole of the spleen became briefly visible instead. The rumen resumed its original size and position immediately after the contraction. There were $9.5 \pm 1.8$ contractions in 9 minutes $(1.1$ \pm 0.20 contractions $/ \mathrm{min}$ ) (Tab. 3) and they occurred at the time point $4.0 \pm 0.85 \mathrm{sec}$, lasted 8.2 $\pm 1.04 \mathrm{sec}$ and had an amplitude of $2.2 \pm 0.86 \mathrm{~cm}$.

\section{Left longitudinal groove}

The left longitudinal groove of the rumen separates the dorsal and ventral sacs of the rumen and was identified in all cows based on its typical triangular-notch appearance. It moved dorsally during contraction of the dorsal sac of the rumen in $39(87 \%)$ cows. During the subsequent relaxation, the left longitudinal groove moved very slowly and continually ventrally to its original position. There were $10.2 \pm 1.98$ movements in 9 minutes $(1.1 \pm 0.22$ movements/minute) (Tab. 3) and they occurred at the time point $4.1 \pm 1.81 \mathrm{sec}$, lasted $7.8 \pm$ $1.19 \mathrm{sec}$ and had an amplitude of $5.0 \pm 1.77 \mathrm{~cm}$.

Ventral sac of the rumen (ruminal recess)

The ventral sac of the rumen could be visualised in all cows between the 10th intercostal space and the flank and contractions were recognised in 31 (69\%) cows. Contractions of the ventral sac of the rumen (ruminal recess) were characterized by transient movement of the rumen away from the abdominal wall. There were $7.5 \pm 2.59$ contractions in 9 minutes $(0.8 \pm$ 0.29 contractions/minute) (Tab. 3) and they occurred at the time point $31.1 \pm 7.07 \mathrm{sec}$, lasted $14.3 \pm 4.3 \mathrm{sec}$ and had an amplitude of $3.0 \pm 0.99 \mathrm{~cm}$.

\section{Caudodorsal and caudoventral blind sacs of the rumen}

The caudodorsal and caudoventral blind sacs had the same ultrasonographic appearance as the $\underline{\text { dorsal }}$ and ventral sacs of the rumen and could be identified in all cows because of the prominent coronary pillars between the sacs of the rumen and the respective blind sacs. During contraction of the caudodorsal blind sac, the posterior groove of the rumen, which separates the two blind sacs, moved dorsally along the abdominal wall, at which time the ventral blind sac also moved dorsally. During contraction of the caudoventral blind sac, the posterior groove of the rumen and the caudodorsal blind sac moved ventrally. These contractions were accompanied by a decrease in size of the blind sacs, which caused them to move away from the abdominal wall. Relaxation did not occur between the contractions of the 
caudodorsal and caudoventral blind sacs. Contractions of the caudodorsal blind sacs were seen in $34(76 \%)$ cows (Tab. 3$)$. There were $9.0 \pm 2.75$ contractions $(1.0 \pm 0.31$ contraction $/ \mathrm{min})$ of the dorsal blind sac and $9.4 \pm 2.09$ contractions $(1.0 \pm 0.23$ contraction/min) of the caudoventral blind sac in 9 minutes. They occurred at the time points $6.2 \pm 1.32$ and $21.3 \pm 6.20 \mathrm{sec}$ and lasted $15.1 \pm 4.43$ and $22.9 \pm 6.40 \mathrm{sec}$, respectively.

Primary and secondary contraction cycles

Primary cycles were recognised in all cows. They were deemed complete in 37 (82\%) cows, in which a contraction was seen at all 5 examination sites, and incomplete in the remaining 8 (18\%) cows. Five cows with an incomplete primary cycle only had contractions of the reticulum and ruminal atrium, and three cows only had contractions of the reticulum, ruminal atrium and dorsal sac of the rumen. Secondary cycles were recognised in 22 (49\%) cows.

There were $11.0 \pm 2.12(6-17)$ primary and $4.5 \pm 2.15(1-9)$ secondary cycles in 9 minutes (Fig. 2), corresponding to an average of 1.2 primary and 0.5 secondary cycles per minute. All secondary cycles were complete. The mean ratio between a primary and secondary cycle was 2.4:1.

\section{Discussion}

The phenomenon of reticuloruminal motility has kept researchers occupied for almost 200 years because of the intriguing structure and function of ruminant forestomachs. Flourens (1833) was the first to study ruminal motility in fistulated sheep, and Colin (1854) carried out extensive studies in fistulated cows using internal palpation of the forestomachs to investigate their function. Toussaint (1875) introduced pressure recording as a tool to investigate rumen function by placing balloons into the rumen through fistulae and connecting them to a kymograph. The first complete description of reticular and ruminal motility was made by Wester (1926), who used direct observation, palpation and pressure recordings. These techniques and their modifications have been widely used in cattle by Schalk and Amadon (1928). More recently, investigation techniques were refined by the substitution of electronic pressure-sensitive devices (Dziuk and Sellers, 1955; Reid and Cornwall, 1959). The most recent study was done almost 50 years ago using two healthy non-ruminating HolsteinFriesian cows. Each cow was used for eight experiments, in which pressure measurements were made for two to three hours (Dziuk and McCauley, 1965). Catheters were successively placed through the rumen fistula into the various forestomach compartments including the reticulum and ruminal atrium, dorsal sac, caudodorsal blind sac and ventral sac of the rumen. 
The findings of these early investigations were tabulated and summarised; although the reviewed studies were heterogeneous with respect to design and endpoints, they agreed on several findings that were summarised as follows (Sellers and Stevens, 1966): "After the reticular contractions, the primary wave of contraction passes back over the rumen, resulting in a lifting of the cranial sac, contraction of the cranial, caudal, and dorsal coronary pillars, and compression of the dorsal sac of the rumen. The wave continues over the caudodorsal blind sac, ventral coronary pillar, ventral sac, and caudoventral blind sac, and the cranial pillar may be ventrally displaced at this time". The different studies also agreed that during the secondary contraction cycle, the caudodorsal blind sac sometimes contracts before the dorsal sac, followed by contraction of the ventral sac of the rumen. This suggested that the secondary cycle starts in the caudodorsal blind sac or in its coronary pillars. The sequence of contractions recorded in the present study agreed well overall with published reports; primary cycles started with biphasic reticular contraction, which was followed immediately by contraction of the ruminal atrium. The dorsal sac of the rumen, the caudodorsal blind sac and the left longitudinal groove contracted at practically the same time, after which contraction of the caudoventral blind sac and the ventral sac of the rumen (ruminal recess) occurred. Complete primary cycles were documented in 37 (82\%) cows. Detection of reticular contractions was straightforward in all cows but contractions of the dorsal and ventral sacs of the rumen were more difficult to see. Assessment of reticular motility is therefore crucial for a clinically relevant examination of reticuloruminal motility. Furthermore, these contractions have the highest amplitude, measuring $6.1 \mathrm{~cm}$ on average, and are therefore readily identified. The amplitudes were smaller than in previous studies (Braun and Rauch, 2008), which may have been due to differences in the measuring technique (see Tab. 2, footnote 1). A biphasic reticular contraction signals the start of a primary ruminal contraction cycle even in the absence of ultrasonographically visible contractions at other examination sites. The detection of a reticular contraction and thus a primary ruminal cycle is clinically relevant in cows that generate audible ruminal sounds of low volume that are difficult to hear with a stethoscope placed on the flank. Ruminal sounds are generated when feed with high fibre content is moved along the ruminal wall during contraction of the rumen (Dirksen, 1979). High producing dairy cows fed a ration with a relatively low fibre content produce fewer frictional ruminal sounds than cows fed hay (Constable et al., 1990a). The greatest benefit from ultrasonographic examination of the reticulum is derived in sick cows to confirm auscultatory findings and to differentiate between normal motility, hypo- and hypermotility of the rumen. For instance, of 144 cows with vagal indigestion that underwent ultrasonographic 
examination of the reticulum, $15 \%$ were diagnosed with atony or hypotony, $38 \%$ had normal reticular motility with three to four contractions in three minutes and $41 \%$ had hypermotility with five to 12 biphasic reticular contractions in 3 minutes (Braun et al., 2009). In contrast, of 20 cows with the same disease and examined by the same clinician using auscultation alone, none was diagnosed with normal ruminal motility and only one (5\%) with hypermotility, whereas in $70 \%$ and $25 \%$, atony and hypomotility was diagnosed, respectively (Braun et al., 1990). The reason for this difference is that the rumen was barely audible or not audible because of liquefaction of the rumen content. The clinician should place a hand on the flank in an attempt to verify rumen contractions if ultrasound is not available (Dirksen, 1979).

Ultrasonographic examination of reticular motility may be useful as a non-invasive method of investigating reticuloruminal stasis in cows with ruminal tympany and acidosis (Leek, 1983), endotoxaemia (Eades, 1997), fever and painful conditions (Leek, 1983) and hypo- and hypercalcaemia (Jørgensen, 1998); in these studies, ruminal motility was assessed using invasive pressure measurements.

We recorded 1.2 primary cycles and 0.5 secondary cycles per minute and a ratio of 2.4:1 between primary and secondary cycles, which was slightly greater than the ratios calculated by other investigators. Standing cows that were not eating had a ratio of 1.7:1 (Stevens and Sellers, 1959) and 2:1 (Phillipson and Reid, 1960). In standing sheep and goats, the ratios were 1.6:1 and 1.7:1, respectively (Dziuk and McCauley, 1965) and in bison it was 1.8:1 (Dziuk, 1965). These differences notwithstanding, it appears that the ratio between primary and secondary cycles is similar across various ruminant species.

\section{Conclusions}

The results of this study support the usefulness of ultrasonography for the assessment of reticuloruminal motility in cows. It is non-invasive, straightforward and fistulation is not required, which facilitates the examination of large numbers of cows. These findings are primarily relevant in a scientific context. Simultaneous ultrasonographic examination of the $\underline{\text { reticulorumen at different sites is hardly feasible in the field and is not expected to provide }}$ much more diagnostic information than reticular ultrasonography alone. Ultrasonographic assessment of reticular motility is of major importance from a clinical perspective for diagnosis of reticuloruminal motility disorders, traumatic reticuloperitonitis and vagal syndrome.

\section{Acknowledgements}


The authors thank the animal assistants for looking after the cows, Luzia Trösch, Sonka Krüger and Charlotte Schnetzler for help with ultrasonographic examinations and Lukas Sprenger for technical assistance.

\section{References}

Braun, U., Hausammann, K., Oertle, C.: Hoflund-Syndrom infolge vorderer funktioneller Stenose bei 20 Kühen. Berl. Münch. Tierärztl. Wschr. 1990, 103: 192 - 197.

Braun, U., Götz, M.: Ultrasonography of the reticulum in cows. Am. J. Vet. Res. 1994, 55: $325-332$.

Braun, U., Rauch, S.: Ultrasonographic evaluation of reticular motility during rest, eating, rumination and stress in 30 healthy cows. Vet. Rec. 2008, 163: $571-574$.

Braun, U., Rauch, S., Hässig, M.: Ultrasonographic evaluation of reticular motility in 144 cattle with vagal indigestion. Vet. Rec. 2009, 164: 11 - 13.

Braun, U., Schweizer, A., Trösch, L.: Ultrasonography of the rumen of dairy cows. BMC Vet. Res. 2013, 9: 44.

Colin, G.: Physiologie comparée des animaux. J.-B. Baillière et Fils, Paris, 1854.

Constable, P. D., Hoffsis, G. F., Rings, D. M.: The reticulorumen: Normal and abnormal motor function. Part I. Primary contraction cycle. Comp. Cont. Educ. Pract. Vet. 1990a, 12: $1008-1014$.

Constable, P. D., Hoffsis, G. F., Rings, D. M.: The reticulorumen: Normal and abnormal motor function. Part II. Secondary contraction cycles, rumination, and esophageal groove closure. Comp. Cont. Educ. Pract. Vet. 12, 1990b: 1169 - 1174.

Dirksen, G.: Forestomachs. In: Clinical Examination of Cattle. Ed. G. Rosenberger. Paul Parey, Berlin, Hamburg, 1979, 197 - 220. 
Dziuk, H. E., Sellers, A. F.: Physiological studies on the vagal nerve supply to the bovine stomach. I. Comparison of responses in milk-fed and roughage-fed calves, using a chronic intrathoracic vagal electrode technique. Am. J. Vet. Res. 1955, 16: $411-417$.

Dziuk, H. E.: Eructation, regurgitation, and reticuloruminal contraction in the American bison. Am. J. Physiol. 1965, 208: 343 - 346.

Dziuk, H. E., McCauley, E. H.: Comparison of ruminoreticular motility patterns in cattle, sheep, and goats. Am. J. Physiol. 1965, 209: 324 - 328.

Eades, S. C.: Endotoxaemia in dairy cattle: Mechanism of reticulorumen stasis. Vet. J. 1997, 153: $321-327$.

Flourens, P.: Mémoires. Académie royale des Sciences. Paris, 1833, 12: 483.

Imran, S., Kumar, A., Tyagi, S. P., Kumar, A., Sharma, S.: Ultrasonographic examination of the rumen in healthy cows. Vet. Med. Int. 2011, 840629, doi: 10.4061.

Jørgensen, R. J., Nyengaard, N. R., Hara, S., Enemark, J. M., Andersen, P. H.: Rumen motility during induced hyper- and hypocalcaemia. Acta Vet. Scand. 1998, 39: 331 - 338.

Kaske, M.: Vormagenmotorik und Ingestapassage. In: Physiologie der Haustiere. Hrsg. W. v. Engelhardt, G. Breves. Enke Verlag, Stuttgart, 2005, 326 - 337.

Leek, B. F.: Clinical diseases of the rumen: A physiologist's view. Vet. Rec. 1983, 113: 10 14.

Phillipson, A. T., Reid, C. S. W.: The incidence of pressure waves in the rumen of cattle. Proc. Nutr. Soc. 1960, 19: 27.

Reid, C. S. W., Cornwall, J. B.: The mechanical activity of the reticulo-rumen of cattle. Proc. New Zealand Soc. Animal Prod. 1959, 19: 23 - 35. 
Schalk, A. F., Amadon, R. S.: Physiology of the ruminant stomach (bovine). Study of the dynamic factors. Bull. 216, North Dakota Agr. Expt. Sta., Fargo, 1928.

Schweizer, A.: Ultraschalluntersuchung des Pansens von 45 Kühen verschiedener Rassen. Masterarbeit, Universität Zürich, 2012.

Sellers, A. F., Stevens, C. E.: Motor functions of the ruminant forestomach. Physiol. Rev. 1966, 46: $634-661$.

Stevens C. E., Sellers, A. F.: Studies of the reflex control of the ruminant stomach with special reference to the eructation reflex. Am. J. Vet. Res. 1959, 20: $461-482$.

Toussaint, H.: Application de la méthode graphique à la détermination du mécanisme de la rejection dans la rumination. Arch. Physiol. Normale Pathol. 1875, 2: $141-176$.

Tschuor, A., Clauss, M.: Investigations on the stratification of forestomach contents in ruminants: an ultrasonographic approach. Eur. J. Wildl. Res. 2008, 54: 627 - 633.

Wester, J.: Die Physiologie und Pathologie der Vormägen beim Rinde. Schoetz, Berlin, 1926.

Wyburn, R. S.: The mixing and propulsion of the stomach contents of ruminants. In: Digestive Physiology and Metabolism in Ruminants. Eds. Y. Ruckebusch, P. Thivend. MTP Press, Lancaster, 1980, 35 - 51.

\section{Corresponding author}

\section{Ueli Braun}

Departement für Nutztiere

Winterthurerstrasse 260

8057 Zürich

Fax: +41 (0)44 6358904

ubraun@vetclinics.uzh.ch 


\section{Legend to Figures}

Figure 1: Sequence of contraction of different parts of the reticulorumen in 45 dairy cows (primary cycles). The red bars indicate the average onset relative to the start of the first reticular contraction and average duration of the contractions recorded at the different scanning sites. R1 $1^{\text {st }}, \mathrm{R} 22^{\text {nd }}$ reticular contraction, RA Ruminal atrium, DSR Dorsal sac of rumen, LLG Left longitudinal groove, CDBS Caudodorsal blind sac, CVBS Caudoventral blind sac, VSR (RR)Ventral sac of rumen (ruminal recess). This figure suggests that the ruminal atrium contracts $1 \mathrm{sec}$ after the dorsal sac of the rumen. However, this did not occur in any of the cows; the contractions of the dorsal sac of the rumen and the left longitudinal groove during the primary cycle were always preceded by contractions of the reticulum and ruminal atrium in all cows. The suggestion of delayed reticular contraction is attributable to the use of means in the figure. See text for definition of scanning sites.

Figure 2: Frequency distribution of primary (A) and secondary (B) contraction cycles of the reticulorumen in 45 dairy cows. 